\title{
O PLÁGIO INVENTIVO: REESCRITURA, REENCENAC̄ÃO, REMONTAGEM, RETEATRALIZAÇÃO E REPERFORMATIZAÇÃO
}

\section{The inventive plagiarism: rewriting, re-enectment, assembly, reteatralization end reperformation}

\author{
Alex Beigui \\ Universidade Federal de Ouro Preto - UFOP
}

Resumo: Através do presente artigo, procuramos discutir a ideia de "plágio inventivo" no contexto da cena contemporânea. Para tanto, apresentamos de maneira sucinta um percurso dos elementos que conduziram ao espaço do plágio, suas contradições e diferenças em relação à cópia e a alguns conceitos afins como o de mímesis e o de simulacro. A partir da problemática entre a "originalidade" e a representação, analisamos algumas experimentações, enquanto campo metodológico de criação.

Palavras-chave: plágio inventivo, experimentação, (re)criação em sala de aula.

Abstract: In this article we discuss the idea of inventive plagiarism within the context of the contemporary scenario. Therefore, we briefly present some of the elements that lead to plagiarism, their contradictions and differences in relation to the copy and their related elements as that of the mimeses and the simulacrum. From the constituted problematic between originality and representation, we analyze some of the experimentations that depart from the idea of plagiarism as a creative methodology.

Keywords: inventive plagiarism, experimentation, classroom (re)creation. 
"Narciso debruçou sobre a fonte para banhar-se e viu, surpreso, uma bela figura que o olhava de dentro da fonte. Com certeza é algum espírito das águas que habita esta fonte. E como é belo!, disse, admirando os olhos brilhantes, os cabelos anelados como os de Apolo, o rosto oval e o pescoço de marfim do ser. Apaixonou-se pelo aspecto saudável e pela beleza daquele ser que, de dentro da fonte, retribuía o seu olhar. Não podia mais se conter. Baixou o rosto para beijar o ser, e enfiou os braços na fonte para abraça-lo. Porém, ao contato de seus braços com a água da fonte, o ser sumiu para voltar depois de alguns instantes, tão belo quanto antes. Porque me desprezas, bela criatura? E por que foges ao meu contato? Meu rosto não deve causar-te repulsa, pois as ninfas me amam, e tu mesmo não me olhas com indiferença. Quando sorrio, também tu sorris, e responde com acenos aos meus acenos. Mas quando estendo os braços, fazes o mesmo para então sumires ao meu contato. Suas lágrimas caíram na água, turvando a imagem. E, ao vê-la partir, Narciso exclamou: - Fica, peço-te, fica! Se não posso tocar-te, deixeme pelo menos admirar-te.". 1
${ }^{1}$ Narrativa do mito de Narciso. http://www.overmundo.com.br/banco/olharinterno-uma-dose-coerente-de-narcisismo. Acessado em 19/02/2018.
Ich plagiiere, also bin ich! ${ }^{2}$

Alguns temas ao longo da história da arte tem sofrido certo tipo de repúdio que, quase sempre, vem atrelado à visão pouco esclarecida do que se entende por "senso comum". O senso comum na Estética foi alvo de constante combate por parte de uma visão elitista em perceber e estratificar os modos de representações artísticas. As hierarquias estabelecidas pela noção de padrão, de beleza, de forma, de escola e de estilo justificam-se por uma premissa que distancia o gosto do senso comum do gosto acadêmico. $\bigcirc$ problema crucial dessa premissa é que ela obscurece a razão crítica e investigativa sobre o fenômeno, idealizando uma espécie de a priori que determina e direciona o produto para um determinado fim, pouco explicando os componentes estruturais e contextuais de

2 “Plagio, logo existo!". Alusão direta ao pensamento cartesiano: "Penso, logo existo!". Em alemão existe uma outra possibilidade: 0 verbo fälschen que não se restringe apenas ao verbo plagiieren - "Ich fälsche, also bin ich!", ou seja "Cópio, logo existo" com sentido mais amplo que plagiat e menos pejorativo, incluindo uma conotação paródica. $O$ ativista sueco Peter Sunde kolmisoppi, co-fundador da Pirate Bay, foi quem cunhou a expressão "Copio, logo existo". 
intersecção entre as obras, sua genealogia de formação, entre autores, entre produtores e entre públicos. Durante muito tempo, a cultura popular foi alvo desse rebaixamento, herança de uma falta de compreensão acerca dos mecanismos da oralidade, do grotesco, do cômico e o do feio com ela incansavelmente e intencionalmente associados.

O esforço empregado em distanciar a partir da, hoje antiquada, ideia de gênero aquilo que é da ordem do popular/populacho, da rua, do espaço aberto de representação; daquilo que é da ordem da elite/culta, dos salões, do espaço fechado de representação, foi questionado contundentemente por Mikhail Bakthin em seu clássico $A$ cultura popular na ldade Média e no Renascimento: 0 contexto de François Rabelais (1987). Com ele aprendemos que a noção de fronteira entre os espaços estéticos acompanha o dentro e o fora da cultura, bem como é no hibridismo dessa relação que se suspeita, cada vez mais, do "suposto original".
A noção de fronteira entre os espaços estéticos e os espaços culturais e de hibridização é a tônica do pensamento bakthiniano. A necessidade de revisitar obras clássicas da literatura e nelas encontrar elementos associativos presentes no imaginário popular fez ruir de uma vez por todas o muro ideológico que separara o espaço do dentro e o espaço do fora da cultura. No esteio desse pensamento, os defensores do "método da comparação", enquanto ferramenta e campo de conhecimento e de embate, viu-se obrigado a rever seus pressupostos de hierarquização, firmados na relação obra-fonte/obraderivada. Dito de outra forma, os adeptos do método da comparação foram impelidos a alterar suas perspectivas de análise. Se antes se partia do conjunto de semelhanças existentes entre duas ou mais obras artísticas, observando seus níveis formais e de conteúdo, passara-se a observar o conjunto de diferenças que compõem a obra, quase sempre, alterada e atualizada social e esteticamente. Em outras palavras, por trás e paralelo à estrutura 
sagrada existe uma estrutura profana e de derrisão, entre o trágico (superior) e o cômico (inferior) há uma linha tênue de demarcação. Para Mikhail Bakhtin,

as fronteiras entre as literaturas oficial e não-oficial deviam finalmente cair nessa época, em parte porque essas fronteiras, delimitando os setores-chave da ideologia, atravessavam a linha de divisão nas línguas: latim e línguas vulgares. A adoção das línguas vulgares pela literatura e certos setores da ideologia devia temporariamente destruir ou pelo menos diminuir essas fronteiras. Toda uma série de outros fatores, resultantes da decomposição do regime feudal e teocrático da Idade Média, contribuiu igualmente para essa fusão, essa mistura do oficial com o nãooficial. (BAKHTIN, 1987, p.62).

Nunca é demais lembrar que o esforço em demarcar a obra-fonte implicou em uma premissa não só da "originalidade" como sinônimo de "primeira", mas do status quo e, consequentemente, hierarquia frente à obra/derivada. Por trás desse jogo entre o original e a cópia, a essência e a aparência, o falso e o verdadeiro esconde-se também uma hierarquização entre as culturas em todos os seus níveis, a saber: pátrio, linguístico, político etc.. Logo, a busca em determinar o original traz inevitavelmente uma clara e evidente relação de poder travestida de defesa da fidelidade e caráter autóctone, supostamente inerente à obra.

O problema da autoria apresenta-se paulatinamente no contexto dessa discussão. A cultura letrada sai na frente com o advento da assinatura pelo poder dado ao autor, sendo a sua presença equiparada a um termo de posse, inviolável, cuja amplitude e cujo alcance determinam o domínio do público e do privado, do que está dentro e do que está fora, do que está no alto e no baixo da cultura.

Deriva-se desse modo de pensar a prerrogativa de que aquilo que não possui assinatura está à margem ou fora da história. Sally Price em seu livro seminal Arte primitiva em centros civilizados (2000), criticamente adverte-nos:

De certa forma, a imagem de Picasso é colocada no papel de "original", com a máscara africana representando um segundo lugar surpreendentemente próximo, cujo status depende de sua afinidade com a obra-prima reconhecida. Historicamente, a máscara africana surgiu primeiro e Picasso 
foi influenciado por ela; mas para os visitantes em potencial do Museum of Modern Art, o nome e a fama de Picasso são muito anteriores, e é a máscara africana que lhes está sendo apresentada pela primeira vez. (PRICE, 2000, p.138).

O processo e o modo de distribuição de uma obra de arte inferem diretamente na intensidade de estereótipos e de discriminação que a acompanha ao longo da história. Até a concepção romântica, conhecida por sua efervescência estética, transgressão, sobretudo, em relação à questão de gênero ratificou a ideia de originalidade como qualidade primeira a ser mantida, reforçando a ideia de genialidade atribuída aos seus singulares baluartes. Ainda que presente em todas as fases da história das artes como elemento norteador da criação artística, a originalidade sempre foi campo sagrado, preservado de quaisquer críticas e/ou ameaça por parte da própria crítica. Preservação que não se verifica na produção dos seus artistas prediletos, sempre ferindo esse princípio de originalidade, embora nem sempre admitindo a arte como uma sucessão de cópias e de plágios sucessivos, alternados, inventivos. Essa falta de honestidade intelectual gerou ao longo da história das artes uma ideia de influência muito forte, sempre do maior para o menor, do centro para o periférico, do mais forte para o mais fraco. Postura que mais tarde será tratada como um dos princípios de subalternidade pelos Estudos Culturais.

Em verdade, sabe-se muito pouco sobre a originalidade enquanto categoria de análise, ela se apresenta sempre como uma qualidade, um adjetivo sobre uma obra ou um determinado autor, porém em termos de categoria analítica ela sempre foi mais um selo de reconhecimento que uma qualidade intrínseca à obra. Sua permanência no campo estético foi tão requerida quanto pouco conceitualizada. Espécie de objetivo dos grandes; reconhecida pelos pares e circunscrita aos ciclos de especialistas (sempre ávidos em manter a pureza dos traços originais). A originalidade foi e é mantida no espaço fechado de 
galerias e museus como forma de preservação dela mesma e de sua institucionalização. Desse contexto, surge a figura do curador (guardião da galinha dos ovos de ouro), mediador quantitativo e monetário dos valores etiquetados da tão buscada e pouco explicada, fascinante: "originalidade".

Todavia, paralelamente, a tal busca incansável, e em meio a um verdadeiro ritual de vigiar e punir foucaultianos, é necessário pensar que a originalidade, enquanto sombra, traz, paradoxalmente, à luz o seu duplo e fantasma: a cópia. A cópia emerge, diferentemente de sua prima rica, como forma amplamente estudada, sobretudo, a partir do século XIX e XX, com os adventos do mimeógrafo, da imprensa, da fotografia, do rádio, do cinema e da televisão. Nesse sentido, a reprodutibilidade refletida por Walter Benjamin (1936) ameaçou a prima rica em sua própria casa.

\section{Cópia versus plágio}

O abandono da ideia de originalidade tem como consequência vários fatores condicionantes, dentre eles: a) a insustentável ideia de influência como forma hierárquica de subjugação cultural de uma identidade local a um pressuposto universal; b) a retomada de conteúdos clássicos ao longo da história lidos, relidos e organizados em distintos contextos culturais e estéticos; c) a difusão da imagem como simulacro; d) a dissolução entre ser e parecer; corpo e alma; matéria e substância. A tênue linha que separa aparência e essência desde a modernidade reforçou 0 campo da cópia como formas estéticas de composição. A diferença entre a cópia e o plágio é que a primeira quando assumida se afirma como forma de homenagem ao suposto original, mantendo com ele uma relação cordial e, na maioria das vezes, de subalternidade. Macaquear o de fora para se afirmar enquanto parte do de dentro. Roberto Schwarz cunhou o verbo em seu livro Ao vencedor às batatas: forma literária $e$ processo social (1977). Trata-se de uma questão crucial no contexto nacional enfrentada por autores como Antonio Candido, Silviano Santiago, Roberto Da Mata, entre 
outros. Esses autores parecem apontar o lugar da cópia no contexto nacional como uma estratégia de sobrevivência - inadequada e paradoxalmente necessária - diante do outro.

Copiar, nesse sentido, revela a condição de um lugar, isto é, a reprodução como modo de selar o poder do colonizador sobre o colonizado. Nesse sentido, o copiado é preso ao "suposto original", fonte de saber, de poder e de reconhecimento. O campo da cultura latino-americana e dos países subdesenvolvidos e/ou em desenvolvimento tornou-se campo expandido da prática da cópia e da contravenção como modo de legitimar sua posição. O que persiste na hierarquia original/cópia é a conturbada relação identidade e alteridade, mediada pelos modos de emissão, produção e recepção.

A cópia é o espelhamento de uma cultura hegemônica e não um modo de democratização, de partilha de saberes, como defendida por alguns autores. A cópia não altera a relação de hierarquia entre culturafonte e cultura-subalterna. Ela reverencia e dinamiza a ilusão que separa 0 mundo das essências (substâncias) do mundo das aparências (formas). Logo, ela reproduz, sem ferir, as linhas demarcatórias que sustentam a distância entre o "suposto original" e a sua falsificação. A cópia é uma das etapas inconsciente do plágio.

Quando falamos de um "suposto original" é por entender que o pensamento emancipatório, a partir do qual todo texto ou objeto artístico responde a outro texto objeto artístico, deve prevalecer sobre a ideia ingênua de originalidade. Devemos sempre manter um olhar em diagonal acerca das práticas que formulam uma divinização do original. Vale ressaltar que no campo da Literatura Comparada, essa concepção de emancipação vem sendo há muito discutida, debatida e enfrentada por teóricos sérios no campo da Comparação Diferencial, principalmente, a partir dos estudos recentes da pesquisadora alemã, radicada na Suíça, Ute Heidmann. Para Heidmann, a história da literatura comparada deve e precisa ser revista, pois a questão dos 
gêneros poesia, drama, épica, prosa entre outros constitui um vasto campo de reescrituras, releituras, reconfigurações, reescritas e traduções que alteram o sentido do original e os sentidos das obras. Trata-se de um infinito diálogo dentro da linguagem, dificultando manter os parâmetros fixos da sequencialidade ou da primeiridade como sendo norteadores do pré-requisito à originalidade.

O caráter performático dos gêneros que avançam e se hibridizam também pode ser percebido em outras linguagens artísticas como as artes plásticas, as artes visuais e a performance. A própria referência como forma de agrupamento dos recursos, incluindo os níveis semióticos intertextuais fere diretamente 0 princípio de originalidade.

É importante, antes de empreender uma defesa do que estamos cunhando de "plágio inventivo", estabelecer e circunscrever seu caráter obtuso e negativo de persona non grata. Se nas guildas medievais os artistas e artífices iniciavam seus estudos plagiando o mestre; se suas carreiras dependiam diretamente da arte do plágio, nos dias atuais o plágio adquire um caráter judicial e punitivo. O vocábulo plágio provém do latim plagium. ${ }^{3}$ Não por acaso é na cultura

$3 \quad$ Plágio significa copiar ou assinar uma obra com partes ou totalmente reproduzida de outra pessoa, dizendo que é sua própria. O plágio pode ser de qualquer natureza, como em livros, música, obras, fotografias, trabalhos, e etc. O plágio ocorre quando um indivíduo copia o trabalho de alguém e não coloca os créditos para 0 autor original. $O$ plágio é a cópia não autorizada de várias informações, e é considerado crime, previsto no Código Penal Brasileiro, e na lei 9610. O plágio é considerado uma atitude antiética em vários países, e em vários é considerado como crime de violação de direito autoral. O plágio musical acontece quando uma música ou o trecho de uma música são copiados por um artista ou banda. Quando isso é provado em uma ação judicial, a parte que copiou tem que pagar uma indenização ao autor original. Quando um objeto ou pintura é falsificado, com o objetivo de enganar alguém para que pense que se trata do original, estamos perante uma fraude denominada contrafação. Existem também diversos casos de plágio no mundo acadêmico, por exemplo, em faculdades, cursos de pós-graduação, mestrado e doutorado, onde alunos copiam trabalhos e teses de conclusão de outros, em vez de utilizar as citações bibliográficas. Além do mais, copiar trabalhos de outra pessoa, que já tenha feito, é considerado plágio, mesmo com o consentimento do autor. Nos trabalhos acadêmicos, os alunos devem seguir as normas da ABNT, que afirmam que mesmo nos pequenos trechos que não são da autoria do executante do trabalho, o autor deve ser devidamente identificado, segundo às especificações normativas estipuladas. $\mathrm{O}$ ato do plágio, como consiste numa cópia da propriedade intelectual de outra pessoa, prejudica o desenvolvimento do pensamento crítico de um aluno, consequentemente retardando o seu aprendizado. Existem vários softwares que detectam plágio, que podem ser online, ou seja, detectar plágio na internet, varrendo sites, por exemplo, e 
romana e não grega que a palavra se consolida e entra em uso. Os gregos parecem desconhecer o seu sentido dentro da cultura. Contribui para isso, a estrutura rica em transposições, apropriações e o caráter inovador dos romanos frente aos gregos, esses últimos presos sobremaneira à rigidez e à ideia platônica de mimese, de modelo, de ordem e de perfeição, assim como de seus graus de formalidade e de constituição. Os romanos parecem entender desde sempre o caráter inovador e cultural implicados no plágio. Parece ficar claro que o plágio para os romanos já em sua etimologia corresponde e traz consigo um modo de assimilação da cultura do outro como ato simultâneo de absorção e de desvio.

Para os romanos, era uma qualidade a ser preservada e até mesmo estimulada, uma vez que a partir dele todo um conjunto de símbolos e de valores podem ser

softwares pessoais, onde a pessoa pode colocar a informação que deseja obter e o software procura em diversas fontes. https://www.significados.com.br/plagio/.

Acesso em: 19/02/2018. ressignificados culturalmente. Os romanos eram excelentes nesse tipo de plágio inventivo-apropriativo. Talvez não seja o momento de denunciar uma cultura do plágio, mas de pensar e de repensar sua função dentro da cultura contemporânea, pós-internet, pensar seus modos de funcionamento em rede e em sistemas de ensino-aprendizagem, pensar sua função no modo como aprendemos, como funcionamos, como entendemos e como existimos. O problema do plágio parece estar mais ligado aos mecanismos de punição do que propriamente de seus efeitos negativos. Com base no pressuposto que aprendemos imitando, é possível entender que o plágio passível de pena é apenas uma das facetas do plágio, pois dentro do processo de criação também compreendemos por meio de imitação. Nessa direção, apresentamos uma experiência estética, por mim conduzida em sala de aula a partir da noção de "plágio inventivo". Como afirmamos, anteriormente, a cópia se difere do plágio porque ela ocorre de modo inconsciente, no sentido de Walter 
Benjamim, opera uma dessacralização do culto ao original por meio da reprodução da imagem. Ela rompe com o valor de eternidade contido no original e primeiro. Segundo o autor:

$\mathrm{O}$ aqui e agora do original constitui o conteúdo da sua autenticidade, e nela se enraíza uma tradição que identifica esse objeto, até os nossos dias, como sendo aquele objeto, sempre igual e idêntico a si mesmo. A esfera da autenticidade, como um todo, escapa à reprodutibilidade técnica, e naturalmente não apenas à técnica. Mas, enquanto o autêntico preserva toda a sua autoridade com relação à reprodução manual, em geral considerada uma falsificação, o mesmo não ocorre no que diz respeito à produção técnica, e isso por duas razões. Em primeiro lugar, relativamente ao original, a reprodução técnica tem mais autonomia que a reprodução manual. Ela pode, por exemplo, pela fotografia, acentuar certos aspectos do original, acessíveis à objetiva - ajustável e capaz de selecionar arbitrariamente o seu ângulo de observação -, mas não acessíveis ao olhar humano. Ela pode, também, graças a procedimentos como a ampliação ou a câmara lenta, fixar imagens que fogem inteiramente à ótica natural. Em segundo lugar, a reprodução técnica pode colocar a cópia do original em situações impossíveis para o próprio original. Ela pode, principalmente, aproximar do indivíduo a obra, seja sob a forma da fotografia, seja do disco. A catedral abandona seu lugar para instalar-se no estúdio de um amador; o coro, executado numa sala ou ao ar livre, pode ser ouvido num quarto. (BENJAMIN, 1985, p.167-168)

O que o autor chama atenção é para a autonomia da reprodução técnica em relação à reprodução manual, evidenciando o nível de atenção requerido sobre o "original" que só o aparato técnico é capaz de alcançar. Defendemos que o plágio inventivo promove o mesmo nível de atenção e de observação, acrescentando categorias criativas. Nele, faz-se necessário aprender as técnicas contidas na obra referente, seu contexto de produção e de recepção. Nos últimos anos, temos experimentado dinâmicas de criação advindas da técnica do plágio inventivo como espaço de composição criativa nos campos da mitocrítica, do teatro, da dança, do cinema e da performance e também de alguns ícones da cultura de massa. Reencenar, no contexto do plágio inventivo, exige uma reprodução técnica consciente da partitura com vistas ao desenho dramatúrgico da ação cênica. 


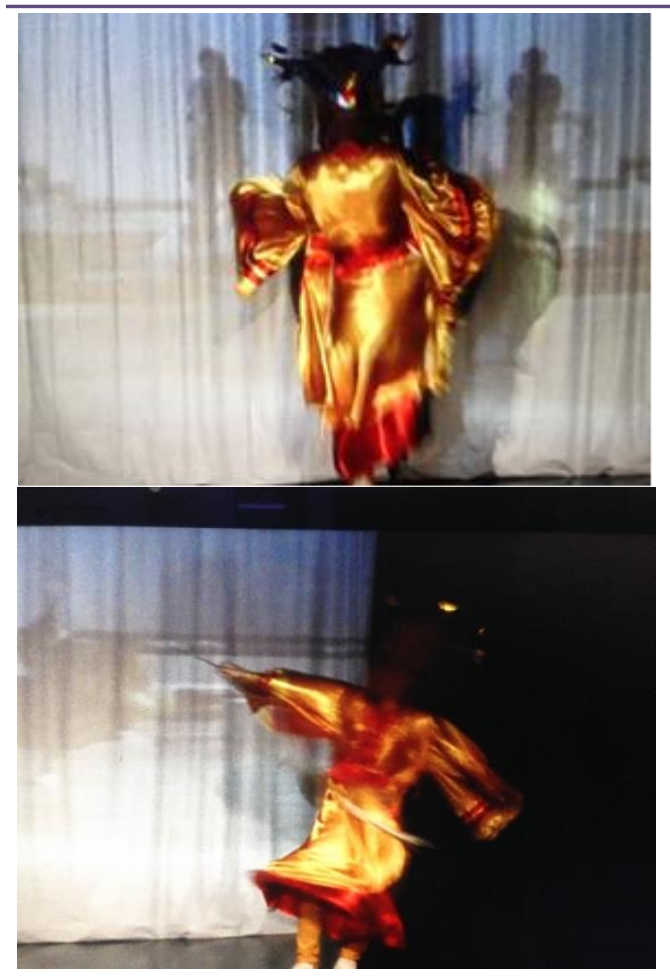

Plágio inventivo da obra Soudain dês nuits d'éveil (1997-1998) de Ariane Mnouchkine Théâtre Du Soleil, realizado pelo discenteintérprete-criador Thazio Silva Bezerra de Menezes. lluminação: Laura Figueiredo. Foto: Lu Paixão. Realizado em 2017

$\mathrm{Na}$ qualidade de coordenador do processo, é preciso que a aulaensaio-espetáculo contextualize os procedimentos envolvidos na transposição do "suposto original", assim como que 0 ato de plagiar intensifique os níveis de consciência entre as referências, as citações e os processos envolvidos na remontagem. Todo trabalho com o plágio inventivo incentiva os discentes-intérpretes a identificar as qualidades estéticas e as referências utilizadas na composição escolhida. A escolha do material é livre, mas obedece há alguns critérios. Os discentes-intérpretes devem ser acompanhados pelo Grupo, nem todos estarão em cena, mas devem assessorar em todas as etapas de criação do plágio. Não é necessário que 0 grupo remonte todo 0 espetáculo, alguns optam por uma cena curta dentro do trabalho, uma vez que o objetivo não é copiar, mas à luz do fragmento identificar, discutir e experimentar estéticas de diferentes tradições cênicas. $O$ exemplo acima é uma exceção. Nele, - grupo decidiu remontar toda a partitura do "suposto original", confeccionou o figurino, a máscara e trabalharam a partir do tema que emergiu da cena, a saber: a influência do teatro oriental no ocidente. 


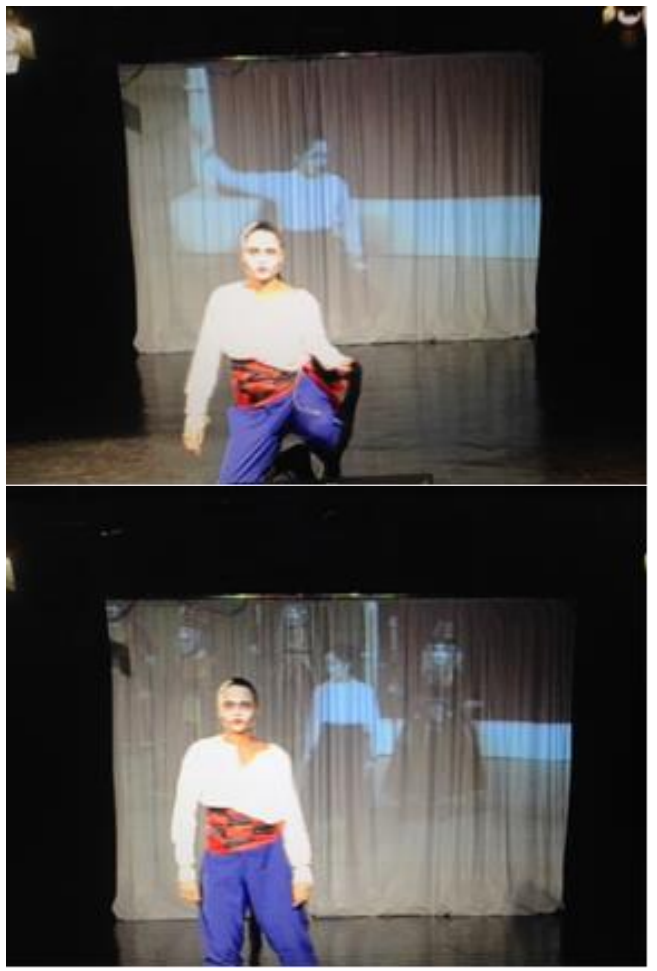

Plágio inventivo da obra Les Atrides Agamemnon (1990-1993) de Ariane Mnouchkine - Théâtre du Soleil. Discenteintérprete-criadora: Prisciane Cunha Rosa da Silva. Iluminação: Laura Figueiredo. Foto: Lu Paixão. Realizado em 2017.

Em Agamenon, percebemos os níveis de dificuldade ao se partir de uma referência estabelecida como modelo. A dificuldade da partitura abriu o campo da discussão acerca de quais técnicas sustentam os temas abordados pelos encenadores modernos e contemporâneos. Em todos os plágios inventivos, parte-se do construto cênico para o estudo das redes e conexões envolvidas na composição, inclusive o estudo do histórico teatral advém da cena plagiada. Embora, a indicação seja evitar o desvio, ele inevitavelmente aparece e, imediatamente, transforma-se em dispositivo de análise e de debate. $O$ desvio erguese a partir de um conjunto de dificuldades, entre elas: espaço, tempo, ação, personagem e relação com o espectador. Todos os grupos avaliam o grau de precisão e de proximidade, bem como as assimetrias que inevitavelmente surgem na justaposição obraplagiada/obra-refente.
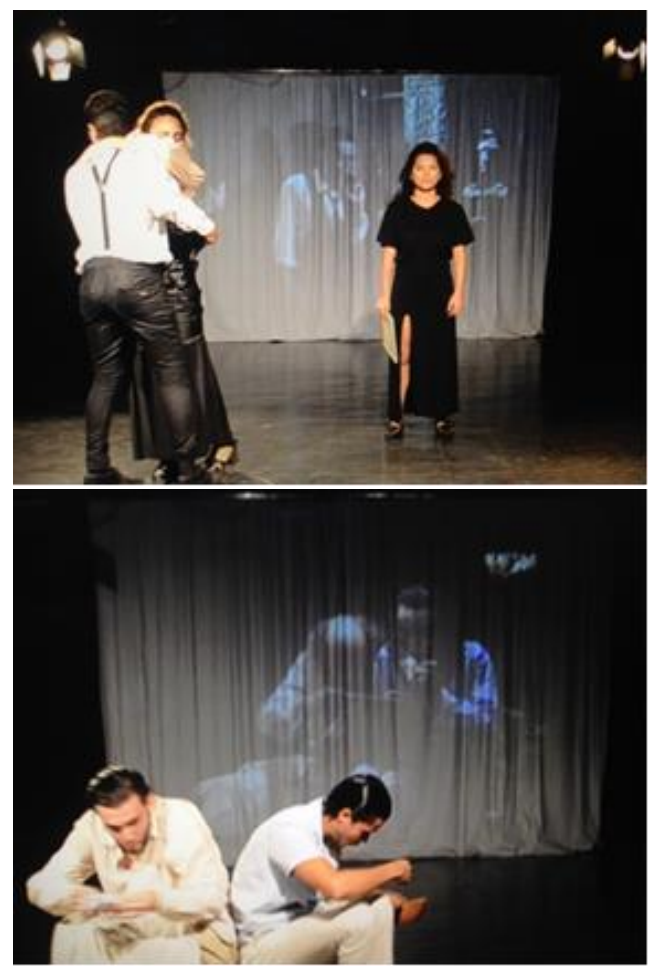

Plágios inventivos das obras Vau da Sarapalha (1992-2006) de Luis Vasconcelos - Teatro Piollin e Carmem com Filtro 2 (1989) 
de Gerald Thomas - Companhia Ópera Seca. Discentes-intérpretes-criadores: no plano alto da esquerda para direita: José Eduardo Pereira de Medeiros e Mychell Ferreira. No plano baixo: Andreza Paulino (frontal), na direita: Bruno Barbosa e Talita Tâmara. Iluminação: Laura Figueiredo. Foto: Lu Paixão. Ambos realizados em 2017.

Nesse tipo de procedimento é preciso pensar o plágio não como cópia, mas como resultado da consciência que se tem acerca dos mecanismos e procedimentos de atuação em jogo, dramaturgia, cenografia, iluminação, sonoplastia, Escola Estética etc. Plagiar uma cena de uma obra como Vau da Sarapalha, por exemplo, espetáculo há mais de duas décadas em cartaz exige um adensamento nas questões estéticas e nas correntes que engrenaram a montagem, tais como: a vinculação do Grupo Piollin ao ISTA-Odin Teatret (International School of Theatre Anthropology) de Eugenio Barba, o treinamento do pré-expressivo, sua entrada no contexto brasileiro, via Luís Otávio Burnier e as consequências para a poética da cena contemporânea. Outro fator importante na composição que tem 0 plágio inventivo como estratégia de criação é que os discentes envolvidos passam

a conhecer cronologicamente a evolução da história da encenação, sem passar por uma sequencialidade de datas, mas enfatizando a identificação dos fatores que contribuíram para a evolução da cena. Aspectos centrais e estruturais da cena aparecem inevitavelmente e, logo, são trazidos em forma de questionamentos e de procedimentos.

Os aspectos periféricos também emergem na composição do plágio inventivo. No fragmento de Carmem com Filtro 2, o contexto da pós-modernidade dos trabalhos de Gerald Thomas surge como parte do material pesquisado. $O$ limite entre história e ficção, memória e realidade, a discussão do realismo no teatro e suas reverberações no cinema surgem do olhar sobre a cena. O tema do teatro como sendo as memórias individuais e coletivas, em ruínas, de uma civilização em crise ampliou o horizonte teóricometodológico da visão e do repertório crítico dos envolvidos frente o construto de Thomas. As fronteiras entre relato e cena; vida e obra; história e discurso instauram 
consequentemente um diálogo cultural entre as imagens justapostas e sua recepção pelos discentescriadores em sala de aula.

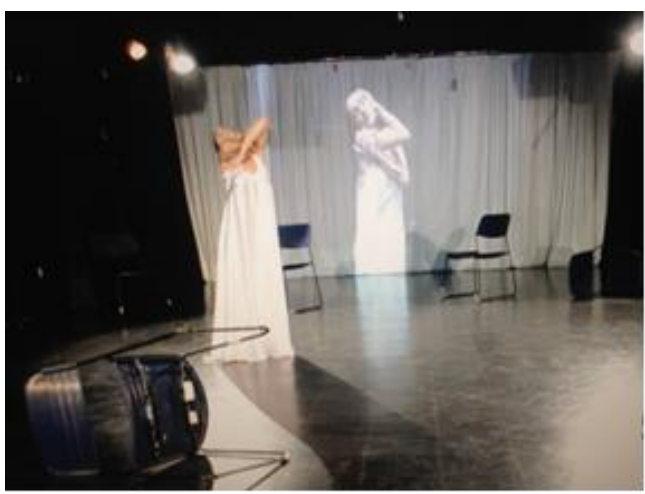

Plágio inventivo da obra Café Muller (1978) de Pina Bausch -. Companhia Tanztheater Wpperthal. Bailarina-discente-criadora: Karina Borja. Iluminação: Laura Figueiredo. Foto: Lu Paixão. Realizado em 2017.

\section{O problema do plágio} corresponde diretamente à difusão da imagem e aos mecanismos de montagem e de remontagem, já percebidos nas obras de Marcel Duchamp e Andy Warhol e que teve sua origem mais sistemática nos estudos de Serguei Eisenstein, ao introduzir projeções em suas peças, criando entre a linguagem cinética e teatral relações possíveis. A experimentação entre imagem teatral e imagem cênica criou uma tensão em relação ao duplo da linguagem, a duplicação da imagem gerou a possibilidade do ator dialogar com ele (seu duplo) em tempo real e do encenador utilizar procedimentos de outra linguagem como concepção de montagem e remontagem. Experimentos que como bem demonstrou Vanessa Teixeira de Oliveira em seu interessante livro Eisenstein ultratetaral (2008) mudaram a relação entre o cinema e o teatro. Segundo a autora:

Esse jogo entre tela e cena é
muito interessante, pois com ele
Eisenstein amplia o poder da
montagem em seu espetáculo ao
tentar articular o jogo do ator em
cena com o duplo dele projetado
na tela, e ao confrontar
espaço/tempo cinematográfico e
espaço/tempo teatral, para ficar
apenas nesses dois pontos.
(OLIVEIRA, 2008, p.134)

A ideia do "Plágio criativo", por mim trazida, extrapola a questão da arte $\mathrm{e}$ isso todos nós sabemos. Trata-se de um campo minado, delicado e complexo de investigação. Nossa intenção em trazer à tona como tema de estudo, de experimentação e de reflexão tem como objetivo discutir sua natureza didática em processos de sala de aula e de discussão dos 
procedimentos, dos princípios e dos mecanismos de composição.

O plágio como matéria crítica de criação permite olhar a tradição e o "suposto original" como meio de investigação das bases que alicerçam a representação no seu jogo de duplos, mimese, cópias e simulacros. A duplicação na arte é uma matéria antiga e controvérsia, ela responde diferentemente aos modos de emissão, produção e recepção de cada época. Evidente está que a questão extrapola o campo da legalidade e se adentra no espaço sócio-educativo.

A própria cultura, para o bem e para o mal, move-se em uma sucessão de plágios ao longo da história. Importa pensá-la no contexto do ensino-aprendizagem como problematização do real, da originalidade, da referência e da citação. Ampliando 0 exercício proposto com os discentes, sugerimos também o plágio cultural como espaço de crítica, a partir da utilização da mídia no jogo das representações sociais. Tanto o construto de Pina Baush (última imagem acima), quanto o referente ao samba no contexto da globalização a partir da imagem da globeleza (última imagem abaixo), foram propostos no Componente Curricular da Especialização em Dança Práticas de Improvisação para a Cena das Danças Contemporâneas. Cada discenteintérprete escolheu a cena artística e/ou midiática que desejava plagiarinventar.

Entendemos que o plágio inventivo como procedimento metodológico envolve não apenas a fase da escolha livre do objeto artístico, teatral, coreográfico, performático, fílmico, midiático, mas a fase da justificativa pelo "supostooriginal". Nessa escolha está implicada a consciência acerca dos fatores formais e contextuais de cada objeto e/ou produto, assim como o modo de constituição de sua conjuntura contextual. 


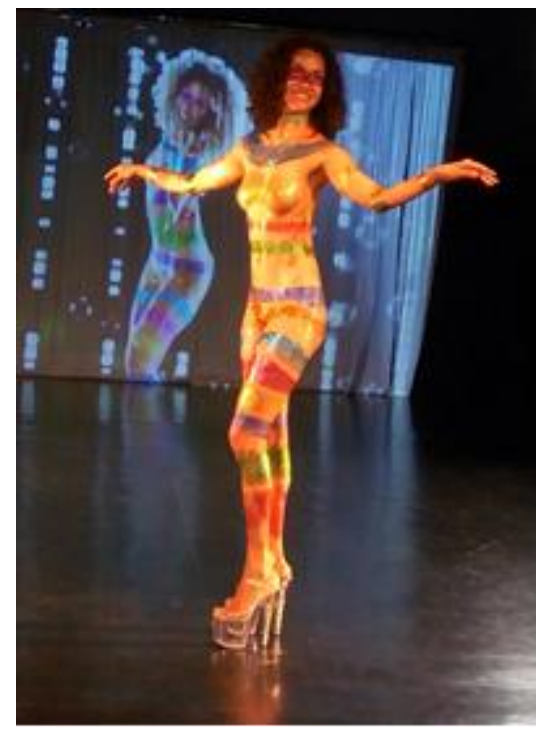

Plágio inventivo da vinheta da Globeleza (Globo, 2017): Dançarina-intérprete-criadora: Andressa Karla da Silva Oliveira. Iluminação: Laura Figueiredo. Foto: Lu Paixão. Realizado em 2017.

O Plágio inventivo, consciente da citação que está em jogo, amplia a capacidade crítica do discente para além da mímesis e/ou da cópia, ele tenciona espaços alternados, criando um não lugar, um intervalo entre o passado da obra plagiada e o presente do plágio inventivo. Além dos aspectos formais, o plágio consciente evoca a ideia de temporalidade descontínua, ou melhor, a um tempo reordenado no fazer e no pensar da citação como campo relacional fora da dicotomia: legítimo ou ilegítimo. A consciência de que todo espaço de representação é sempre repertoriado melhor condiz com a impermanência que rege não só os modelos e os gostos de nosso tempo, mas também que regem a composição de obras artísticas, de objetos e de produtos culturais. Para Marc Augé, "o lugar e o não lugar são, antes, polaridades fugidias: o primeiro nunca é completamente apagado e o segundo nunca se realiza totalmente - palimpsestos em que se reinscreve, sem cessar, o jogo embaralhado da identidade e da relação" (AUGÉ, 2012, p. 74.). mais importante a dizer sobre 0 plágio inventivo é que ele exige uma prática e uma reflexão.

Para tanto, é necessário dominar a técnica presente no "suposto original", manter com ele uma certa intimidade, estar aberto a perceber as suas lacunas. Muito se tem falado, no seio da crítica da arte em "estado da arte". Mas o que é o estado da arte se não o confronto com os seus duplos e suas apropriações? Ele é o espaço dos múltiplos desvios que sucedem uma cadeia de repertório. Plagiar talvez seja o primeiro contato efetivo com a referência, não a referência que discentes e pesquisadores da 


\begin{abstract}
América Latina e de países periféricos ouviram falar ou viram através dos livros ilustrados, ou mesmo das paisagens virtuais de museus com livre acesso em rede, mas de uma experiência que o obriga a criar sobre o criado e

Lúcia Pereira. Campinas-SP: Papirus, 2012.

BAKHTIN, Mikhail. A cultura popular na Idade Média e no Renascimento: o contexto de François Rabelais. Trad. Yara Frateschi Vieira. São Paulo: HUCITEC: Editora da Universidade de Brasília, 1987.
\end{abstract} perceber esse processo no seu próprio contexto de artista, como advindo de uma cadeia de sucessivas réplicas, releituras, perguntas e respostas. O objetivo desse trabalho não é o de dar conta do plágio, campo tão vasto de abrangência, mas alicerça-se na direção de aceitar uma provocação advinda daqueles que visando estreitar ou impedir o debate repetem incessantemente "plágio é plágio". O verbo ser, no sentido afirmativo deveria ser banido de qualquer ambiente que priorize a reflexão, pois ele é tão curto e limitado em sua grafia, quanto efêmero em seu sentido.

Recebido em 30/08/2018

Aceito em 20/11/2018

\section{Referências Bibliográficas}

AUGÉ, Marc. Não lugares: introdução a uma antropologia da supermodernidade. Trad. Maria
BENJAMIN, Walter. Obras escolhidas: magia e técnica, arte e política. Trad. Sergio Paulo Rouanet. São Paulo: Brasiliense, 1985.

HEIDMANN, Ute. Mythes (ré)configure's: création, dialogues, analyses. Lausanne, CLE-UNIL, 2013.

OLIVEIRA, Vanessa Teixeira. Eisenstein ultrateatral. São Paulo, Perspectiva, 2008.

PRICE, Sally. Arte primitiva em centros civilizados. Trad. Inês Alfano. Rio de janeiro, Editora UFRJ, 2000. 
Moringa Artes do Espetáculo, João Pessoa, UFPB, v. 10 n. 1, jan-jun/2019, p. 111 a 128

\section{morinda}

